\title{
Effectiveness and Efficiency of RFID technology in Supply Chain Management: Strategic values and Challenges
}

\author{
Asghar Sabbaghi $^{1}$ and Ganesh Vaidyanathan ${ }^{2}$ \\ Indiana University South Bend, School of Business and Economics, \\ ${ }^{1}$ sabbaghi@lusb.edu, ${ }^{2}$ gvaidyan@iusb.edu \\ Received 4 August 2007; received in revised form 29 January 2008; accepted 22 April 2008

\begin{abstract}
In this study, we examine the fundamental components of RFID technology in a comprehensive supply chain strategy that directly support the effectiveness and efficiency of supply chain management. We examine the appropriate business processes affected by the RFID technology, the required planning and examination for successful implementation, and many potential impacts on effectiveness and efficiency of supply chain management. We emphasize on business values and strategic advantages of RFID technology as well as the challenges and recommendations in adoption of the technology particularly when a company extends its supply chain to upstream suppliers and downstream customers, as their external integration needs to gain in capacity planning and in efficiency. Using four major supply chain processes, we highlight economic opportunities and challenges when planning and implementing RFID technology within an existing supply chain framework. We will focus on the capabilities of RFID in providing security, privacy, and integrity of supply chain processes while facilitating sharing information with upstream suppliers and downstream customers, developing alliances, establishing strategic alliances, and gaining competitive advantages.
\end{abstract}

Key words: RFID, Process, Effectiveness, Efficiency, Supply chain management, Values, Strategy 


\section{Introduction}

The applications of Radio Frequency Identification (RFID) and Electronic Product Codes (EPC) in supply chain management have vast potential in improving effectiveness and efficiencies in solving supply chain problems. EPC is the concept of storing product identification on chips no larger than a grain of sand, then placing these chips on tags, which in turn are placed on objects so they can be uniquely identified. RFID technology can track inventory more accurately in real time resulting in reduced processing time and labor. There are many applications and possibilities for RFID/EPC as these objects in motion are traced throughout the supply chain. The complete visibility of accurate inventory data throughout the supply chain from manufacturer's shop floor to warehouses to retail stores brings opportunities for improvement and transformation in various processes of the supply chain. RFID technology can help a wide range of organizations and individuals such as hospitals and patients, retailers and customers, and manufacturers and distributors throughout the supply chain to realize significant productivity gains and efficiencies.

In this study we try to answer the following questions: (1) what processes in supply chain will be affected by RFID technology and where this technology has the potential of creating the most business values? (2) Given the integrated and interdependencies of supply chain processes, what would be the capabilities of RFID in providing security, privacy, and integrity of processes while facilitating sharing information with customers and suppliers, developing strategic alliances and ultimately gaining competitive advantage? (3) What are the challenges and recommendations in adopting and implementing RFID technology in supply chain?

We examine the fundamental components of RFID technology as parts of a comprehensive supply chain strategy that directly support the effectiveness and efficiency of supply chain management. We will examine appropriate business processes in supply chain affected by RFID Technology and will identify processes where RFID plays a critical role in creating the most value. In particular, we highlight the many business values and strategic benefits of RFID technology as well as the many challenges and recommendations in adoption and implementation of the technology in the context of integrated and interdependencies of supply chain processes.

\section{Literature Review}

RFID technology has been promising to enhance support supply chain management efforts [13], [14], [28], [29]. The future success of RFID and other mobile services will be strongly affected by the ability of businesses to offer the right products and services to consumers [1], [6]. RFID has the potential in other areas of operations, such as manufacturing, after-sales service support, and total product life cycle management [18]. An RFID system can be used to identify many types of objects, such as manufactured goods, animals, and people. RFID technologies support a wide range of applications-everything from asset management and tracking to manufactured products and related customer services to access controls and automated payments. Each RFID system has different components and customizations so that it can support a particular business process for an enterprise. Depending on the application in an industry and the enterprise within an industry, A RFID system can be very complex, and its implementations may vary greatly. Conceptually, RFID system may be composed of three subsystems as shown [15] in Figure 1: (1) An RF subsystem, which performs identification and related transactions using wireless communication, (2) An enterprise subsystem, which contains computers running specialized software that can store, process, and analyze data acquired from RF subsystem transactions to make the data useful to a supported business process, and (3) An inter-enterprise subsystem, which connects enterprise subsystems when information needs to be shared across organizational boundaries. Every RFID system contains an RF subsystem, which is composed of tags and readers. In many RFID systems, the RF subsystem is supported by an enterprise subsystem that is composed of middleware, analytic systems, and networking services. However, in a supply chain application, a tagged product is tracked throughout its life cycle, from the manufacture to final purchase, and sometimes even afterwards (e.g., to support targeted product recalls or related service), and thus its RFID systems has to share information across organizational boundaries. Thus, the RFID systems supporting supply chain applications have also an inter-enterprise subsystem.

The enterprise subsystem is the computer system and software that utilizes information stored on RFID tags. It is the glue that integrates an RFID system. Depending on the industry context, but usually a front end component manages the readers and the antennas and a middleware component routes this information to servers that run the backbone database applications. For example, in a manufacturing context, the enterprise software will need to be made aware of RFID at various levels depending on how far downstream into manufacturing and out into the supply chain RFID is implemented. The middleware technologies are categorized into three levels: (1) software applications which solve connectivity problems and monitoring in specific vertical industries, (2) application managers that connect disparate applications within an enterprise, and (3) device brokers that connect applications to devices like shop-floor machines and RFID readers [26]. The Auto-ID Center at MIT developed a software program named 'Savant' to manage the enormous amount of data expected to be generated by RFID readers [3]. In a typical manufacturing scenario, for example, readers will be picking up a continuous stream of tag data, which might contain errors such as duplicate reads and phantom-reads. The job of a savant is to filter and manage this data and forward only clean data 
in order to avoid overwhelming enterprise applications. Applications vary in how they interact with RFID. Some treat RFID reads like keyed data or bar-code scans, and others work specifically with RFID tags.

The application of RFID ranges from manufacturing and distribution of physical goods such as automobiles and its various components to minting bank notes, oil exploration, shipping and port operations and pharmaceutical package processes, among others [2]. RFID is a form of automatic identification and data capture (AIDC) technology that uses electric or magnetic fields at radio frequencies for identification, authentication, location, or automatic data acquisition and transmit, and support a wide range of applications-everything from asset management and tracking to access control and automated payment. RFID systems have the capability of sharing information across organizational boundaries, such as supply chain applications. Reno $\mathrm{GmbH}$, one of Europe's largest shoe companies, operating more than 700 stores in 15 countries, plans to embed wireless RFID chips in shoes sold at stores across the continent. Reno has been using RFID technology to track product shipments from its factories to its stores for several years but has not yet used the technology to track individual products inside each store. These wafer-thin RFID chips are designed especially for shoes from its Asian production facilities. By having the RFID tags integrated into its shoes, Reno aims to curb theft for boxed products, those on display, and the shoes customers try on inside the stores.

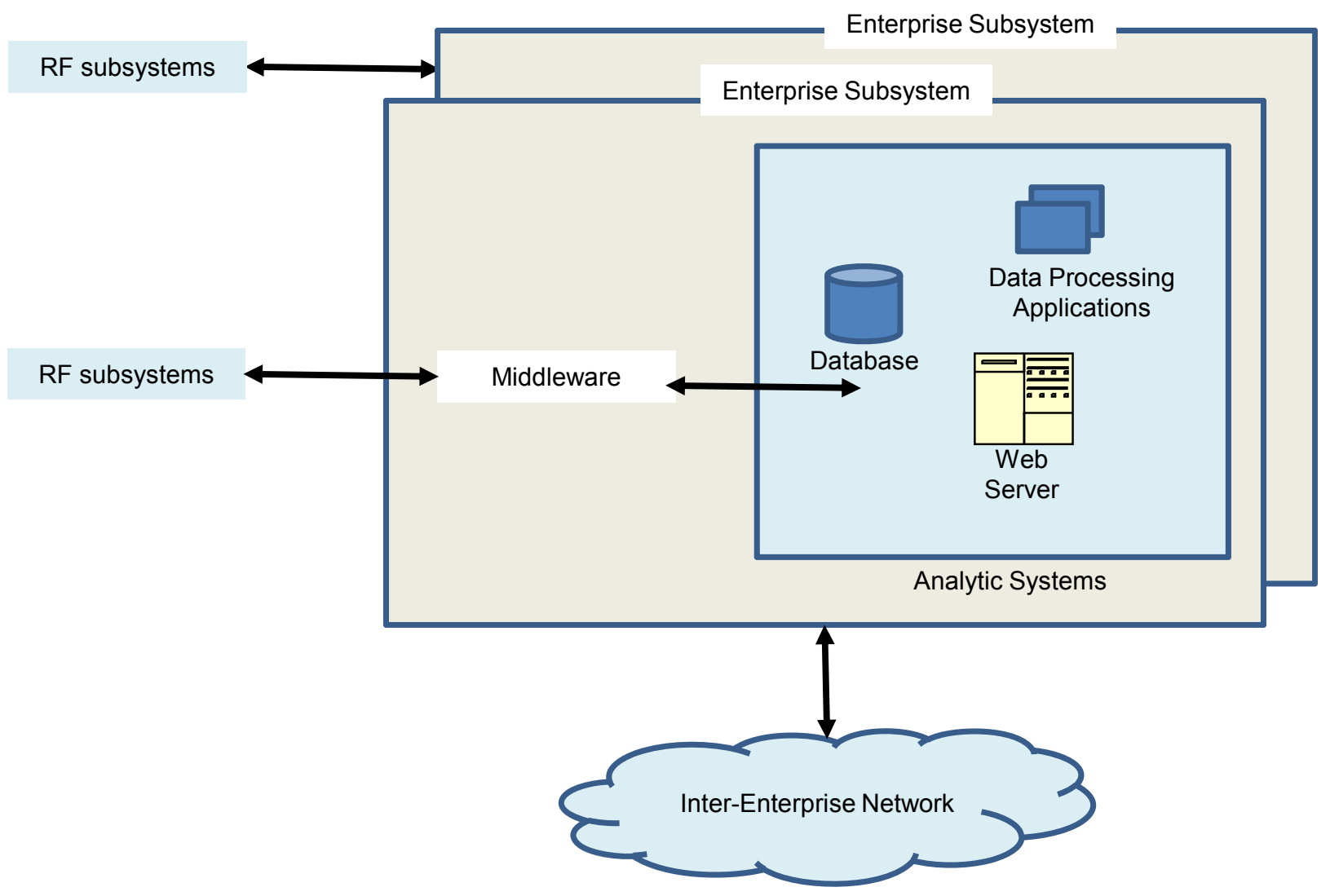

Figure 1: Inter-Enterprise Architecture

In Japan, the RFID chip has become a de facto standard in the last five years, and credit cards containing RFID are used by millions of people every day to make railway travel and e-money purchases. In 2004, the RFID chip by Sony's FeliCa, started getting integrated in cell phones and today owners of those cell phones can make credit card purchases in stores. Tokyo's subway and private railway and bus operators are launching a common travel card based on the FeliCa platform. The Pasmo system will be interoperable with East Japan Railway Co.'s (JR East's) Suica card, allowing the 35 million people who live in the Tokyo Metropolitan area the ability to travel on more than 100 railway lines and hundreds of bus routes with a single card. The touch-and-go payments it supports work over a distance of a few centimeters and take 0.1 seconds for each to complete. In addition to Japan, the technology provides the base for the Octopus subway card in Hong Kong, which has also morphed into an e-money payment system, and the ez-Link transport card in Singapore. FeliCa is also used in Shenzhen's TransCard, India's TravelCard and Bangkok's Metro Card but has yet to break significantly into European or North American markets.

Schiff Nutrition International, a midsize company based in Salt Lake City, maker of vitamins and nutritional supplements, is in the process of a deployment of the RFID technology in order to continue doing business with WalMart [20]. In 2003, Wal-Mart began setting deadlines for suppliers to start using RFID tags on their shipments. While it was argued that the RFID tags weren't resulting in the savings that Wal-Mart expected, many suppliers were 
complaining about the cost of implementing the technology. However, it is expected that the project will ultimately help to build stronger supply chains that cut costs and improve efficiencies.

The International Data Corporation (IDC) has estimated that the RFID market for related consulting, implementation, and managed services was expected to grow $47 \%$ in 2004 and reached $\$ 2$ billion worldwide by 2008 . It was also estimated that two-third of enterprise organizations considering RFID applications in 2004 indicated that they would rely on external resources in implementing RFID. The Yankee group estimates that RFID technology will be a $\$ 4.2$ billion market by 2008. By some estimates, over 1.3 billion RFID tags were produced in 2005, and that figure is estimated to soar to 33 billion in 2010, and by far the biggest segment is accounted for supply chain. However, for a successful deployment of RFID, it is important to have a set of widely accepted standards and regulations. According to McCathie and Michael [21], the progression of barcode standards from proprietary to globally accepted open standards had played a pivotal role in a world wide acceptance of the technology. Therefore, in order to be effective, there has to be standards and regulations in the case of RFID as well. For example, many companies, particularly small-medium enterprises, have reported that RFID is extremely costly in their supply chain. The cost of acquiring, installing, and maintaining an RFID system has been a major and often determining factor in the deployment of RFID in the commercial sector.

\section{Methodology}

In exploring the effectiveness and efficiency of RFID applications, we consider the eight key processes [8], [7] that make up the supply chain management process. These processes provide a framework for various aspects of strategic and tactical issues present in the management of the supply chain. These eight processes and their functions are described as follows:

(a) Customer Relationship Management: Provides structure to customer relationship and how such relationships are developed, maintained, and managed. Identifies target customer groups as part of the business mission and develops agreements with key accounts. Performance reports also measure profitability and financial impact for key customers.

(b) Customer Service Management: Provides customer information such as shipping dates, product availability, and real-time information between customers and the firm.

(c) Demand Management: Balances the customers' requirements with the firm's supply capabilities. This would include forecasting demand and managing the demand in production, procurement, distribution, and in all other outputs of the company.

(d) Order Fulfillment Management: Provides integration of the firm's manufacturing, logistics and marketing plans. This would require the management of partnerships maintained by the company to meet customer requirements.

(e) Manufacturing Flow Management: Helps to manufacture products and establishes the manufacturing flexibility required to service target markets. Requires management of product flow and maintaining the flexibility established.

(f) Supplier Relationship Management: Defines how a company interacts with its suppliers. Similar to customer relationship management, partnership management is required to develop key relationship with core suppliers potentially providing a competitive advantage.

(g) Product Development and Commercialization: Provides the development of new products by integrating customers and suppliers in reducing time to market. Timely development of new products and services are keys to firm's success.

(h) Returns Management: Provides a critical component of sustained competitive advantage for the firm. Allows firm to monitor productivity improvements and identify valuable projects related to products or services.

Out of these eight processes, we have chosen and identified four processes that include demand management, order fulfillment, manufacturing flow management, and return management where RFID plays a critical role and creates the most value. Keen and Mackintosh [16] introduce "process freedom" as those processes with the ability to add value along the entire supply Chain by enabling the mobility of critical elements. These critical elements are business activities, people, information, documents, and communications that are needed for a more effective business process design. Angels [2] argues that RFIDs hold the potential to provide significant "freedom" that will liberate considerable human labor from certain workflows, as well as facilitate the possibility of making information visible to all participants throughout the value chain. 
We will emphasize on business values and strategic advantages of RFID technology as well as the challenges and recommendations in adoption and implementation of the technology particularly when a company extends its supply chain to upstream suppliers and downstream customers, as their external integration needs to gain in capacity planning and in efficiency.

\section{RFID Technology in enterprise systems}

In the 1990s, IBM created companywide organizations for procurement, logistics, fulfillment and manufacturing. In 2002, IBM brought all of those units together under a new Integrated Supply Chain division [11]. The division was credited with helping to cut costs and improve responsiveness within a year. The company had to balance two ways of measuring supply-chain performance: (1) effectiveness: flexibility and responsiveness, and (2) efficiency: lowering costs as much as possible. It was reported in the same paper [11] that the supply-chain optimization effort forced IBM to seek opportunities to balance effectiveness versus efficiency in all four dimensions: (a) data collected at various points in the supply chain, (b) the business processes involved in the supply chain, (c) the information systems involved and $(d)$ the organizations involved in carrying out the various business practices.

In order to measure effectiveness and efficiency, firms need to have a clear picture of the key supply chain processes and a measure of performance in each one of the processes. Companies in many industries, such as fast-moving consumer goods industry, manufactures, consumer electronics, apparel industries, are in their infancy stages in the implementation of new technologies that use EPC and RFID. This technology will extend the abilities of firms to capture accurate information on the location and status of physical objects across the supply chain. The pace of implementation in Wal-Mart has been slower than the giant retailer had predicted due to insufficient infrastructure of supply chain for RFID and the cost of implementing the technology. To better understand supply chain management and RFID technology as well as the opportunities and the challenges, we will discuss supply chain infrastructure, particularly as it relates to the enterprise and inter-enterprise subsystems of RFID systems.

\subsection{RFID in enterprise systems}

The focus of supply chain technologies has primarily been on providing operational and transactional efficiencies in the area of sourcing, manufacturing, and distribution activities within a firm and across its supply chain. According to the Supply-Chain Council, "The supply-chain encompasses every effort involved in producing and delivering a final product or service, from the supplier's supplier to the customer's customer. Supply-chain management includes managing supply and demand, sourcing raw materials and parts, manufacturing and assembly, warehousing and inventory tracking, order entry and order management, distribution across all channels, and delivery to the customer.

Keen and Mackintosh [16] argue that RFID technologies are part of the "universal infrastructure" that will support mobile commerce. They introduced "process freedom", the ability to add value along the entire supply chain, to relate logistical operations and business relationships by enabling the mobility of critical elements that included business activities, people, information, documents, and communications. In this context, the technology holds the potential for providing significant "freedoms" that will reduce considerable human labor from certain workflows as well as for facilitating the possibility of making information readily available to all participants throughout the value chain. However, due to its wide scope, supply-chain management must address complex interdependencies and accordingly be open to reengineer its appropriate processes. Moreover, these processes should create an "extended enterprise" that reaches far beyond the factory door. In effect, material and service suppliers, channel supply partners that include wholesalers, distributors, retailers, and customers, supply chain management consultants, software product suppliers and system developers, become key players in the supply chain process. For a supply chain participant, core competencies and capabilities must enable them to create value in the form of lower cost, improved quality, more flexibility, higher speed, and better information/intelligence about the processes and market forces. In particular, using the concept of business intelligence to data from supply chain management systems, supply chain technologies may be applied to provide strategic information for decision making purposes. In this manner, data collected across the supply chain may be analyzed to provide information for evaluation of the supply chain performance and its reconfiguration, as well as conducting what-if scenarios to measure the effectiveness and efficiency of supply chain.

\subsection{Value of RFID in enterprise systems}

What has been developed and presented as a supply chain within distinct companies has varied widely. In essence, no two companies' supply chains look alike. There are many supply chain models, and these models only effectively deliver on their promise when aligned with the way in which the company wants to go to market. Furthermore, most companies don't merely have one chain. They have many, and several of them are actually networks. As shown in the figure 2, on the basis of business impact and complexity, Cavinato [5] distinguishes sixteen types of supply chains. With respect to complexity, supply chains can range from a very basic form to a very sophisticated complex chain and based on business impact, they range from a very traditional to a supply chain with competitive advantage. As one move toward more sophistication and business impact, at the high end, the emphasis is placed on the model of supply chain with information networks, and on data access that can be converted into information, knowledge, 
and intelligence. RFID technology can support to develop such an integrated model of supply and demand chain or an integrated value chain in which one use the technology to drive revenues and innovation and create value-not just to reduce cost, but to gain competitive advantage.

The major purpose of deploying RFID is identification, authentication, location, or automatic data acquisition (ADA). Authentication applications usually assume the tag-holder to be a person who has smart cards for simple and automatic payments of small amounts such as highway tolls and cafeteria bills rather than an object; whereas most supply chain applications assume that the tag-holder is an object [3]. One of the major thrust of the supply chain applications is ADA. In most ADA applications, objects such as products, cases, and pallets are tracked automatically and the captured data is used to derive enterprise applications such as supply chain management systems, customer relationship management systems, and enterprise resource planning systems. Applications that require identification or ADA, such as RFID tags embedded in athletes' shoes to keep accurate timings at major athletics events, belong to the domain of ubiquitous computing. This concept envisages a world where RFID tags are attached to a multitude of items that automatically communicate and coordinate with other networked intelligent devices to accomplish tasks that now require human intervention [3]. The effectiveness and the functionality of these applications will be largely dependent on the type of tag itself. While some tags offer longer read ranges, others can hold more data or are easier to manufacture hence less costly.

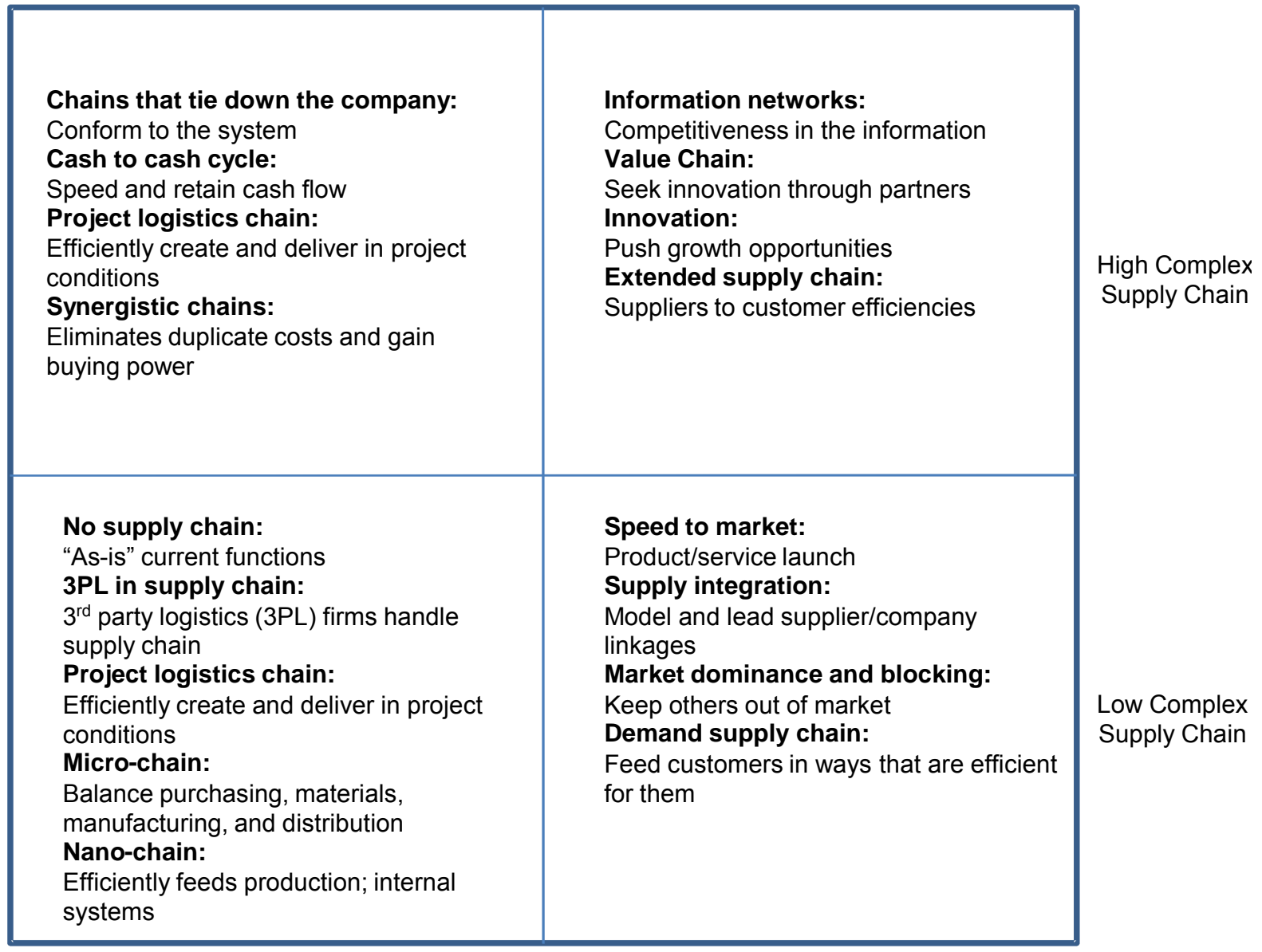

Low Business Impact

High Business Impact

Figure 2: Types of Chains/Networks

As the prices of technology decline and the applications become more economical, RFID becomes very valuable from a productivity point of view. One can see broader efficiency and operational improvements over traditional processes, methods, and technologies. Ford uses a real-time logistics system for visibility through triangulation. Similar to e-commerce, RFID is evolving in application and its impact on effectiveness. Initially, e-commerce was just automating existing processes and work flows. One could send a purchase order by the Internet or pay an invoice or communicate through e-mail, and thus substituting an existing technology for a new one. However, the biggest value in e-commerce is when a company develops collaboration with its suppliers. Microsoft found value in e-commerce when they used the Internet to collaborate to design the Xbox. RFID is following the same kind of evolution path. Currently, RFID may be viewed mostly for efficient tracking. However, the most valuable impact of RFID will be realized from new applications that use the technology's intelligence. As Neubauer, et al [23] note, if businesses view RFID simply as a replacement for barcodes and do not change or redesign their business processes based on RFID's capabilities, the return on investment will be suboptimal. RFID can create a borderless supply chain when 
cargoes are equipped with tags showing the contents, so that customs clearance can be done almost automatically. RFID can also provide supply chain security when RFID tags are used to electronically seal containers and monitor movements of the containers, so that any tampering can be tracked. Finally another important benefit of RFID is to facilitate sharing information with customers and suppliers, developing alliances, innovating with suppliers, and establishing strategic alliances. In other words, RFID can facilitate to develop an integrated supply and demand chain or an integrated value chain in which one uses the technology to drive revenues and innovation and create value-not just to reduce cost, and to gain strategic advantage.

\subsection{RFID standards in enterprise systems}

One of the critical elements of RFID application in supply chain is Standardization for encoding information on RFID tags similar to the current bar codes on Universal Product Code (UPC) system. When one company ships goods to another company, these standards will help simplify the electronic transactions that occur between the organizations' ERP (enterprise resource planning) systems. The standards will determine how middleware handles data scanned by an RFID reader as goods enter a warehouse and will pass the data to an enterprise application. The current version of the EPC Tag Data Standard specifies the data format for encoding and reading data from RFID tags. The data stored in these tags dictates information about a product in UPC terms, including company and product identifiers. Both EPCglobal and International Standards Organization (ISO) have adopted RFID in their standards.

The most prominent industry standards for RFID are the EPCglobal specifications and standards for supply chain. EPCglobal Inc. manages standardization for encoding information on RFID tags. This is the same institution that manages UPC information in bar codes, sets the standards for how basic product information is encoded in the RFID chips. EPCglobal Inc is a nonprofit organization that was initiated in 2003 by the MIT Auto-ID Center in cooperation with other research universities to establish and support the EPC network as the global standard for the automatic and accurate identification of any item in supply chain. EPCglobal will establish the standards on how information is passed from RFID readers to various applications, as well as from application to application, in the supply chain. ISO also has RFID standards. ISO is a network of the national standards institutes of 157 countries, on the basis of one member per country, with a Central Secretariat in Geneva, Switzerland, that coordinates the system. ISO occupies a special position between the public and private sectors. This is because, on the one hand, many of its member institutes are part of the governmental structure of their countries, or are mandated by their government. On the other hand, other members have their roots uniquely in the private sector, having been set up by national partnerships of industry associations. The ISO18000 series covers both Active and Passive RFID technologies. The data content of RFID is covered in ISO 15418, 15434, 15459, 24721, 15961, and 15962. The conformance and performance standards are covered in ISO 18046 and ISO 18047 series for both active and passive RFID technologies.

\subsection{Data synchronization in RFID}

Data synchronization is another important element of supply chain to be addressed by RFID. Companies require detailed information about their products and supply chain, and the ability to share that information with their trading partners in order to facilitate various business transactions and the movement of goods and services. Two distinct information networks have been developed: the Global Data Synchronization Network (GDSN) and the EPCglobal Network. The GDSN ensures the quality of static information about commercial entities and product/service groups among partners for collaborative trading. The EPCglobal Network provides access to dynamic information about the movement of individual items as they pass through the supply chain. The EPCglobal Network and the GDSN each provide significant benefits in their own right. Moreover, for companies striving to achieve a fully collaborative business model, the combination of the EPCglobal Network and the GDSN can provide a comprehensive, integrated approach to electronic collaboration and, as a result, can be complementary in the effort to optimize global trading relationships.

\section{Supply Chain Management Processes and RFID applications}

RFID may be used in demand management, order fulfillment, manufacturing flow management, and return management. In this section, we discuss these four supply chain management processes in detail.

\subsection{Demand management and RFID}

One of the main difficulties in demand planning is a lack of reliable data and adopting RFID would produce accurate information related to the inventory of finished goods, work-in-progress, and in-transit stages with reliable due dates [4]. Data obtained from RFID can eliminate inaccuracies in data due to human error or absence of data. Consumer demand for lower price and higher quality are the driving forces for companies to make their supply chain more effective and efficient. Timely data at the item-level and in aggregate about the market demand for any product/service would help to develop more successful strategies in production, marketing and distribution. The forecast provides the input for matching demand with supply in the form of aggregate planning. This aggregate planning can be enhanced by accurate data using RFID thereby avoiding costly buffer stocks while demand planning. 


\subsection{Order Fulfillment and RFID}

Order fulfillment is a key process in meeting customer requirements and improves the effectiveness of supply chain [17]. RFID will enable process automation in picking, shelving, cross-docking, implementing consolidation operations and reduce costly logistics mistakes such as sending an item to a wrong destination and not dispatching the right item at the right time [4]. Such process changes will reduce the cost of operations. RFID technology enables suppliers to accurately determine the location of a pallet, to track its journey through the supply chain, and to make instantaneous routing decisions. . For instance, RFID portals, mounted in strategic points in the distribution center, can be used to read tags and automatically update inventory quantities as tagged cases and pallets enter the center. The incoming merchandise will be matched against the correct purchase order and discrepancies will be identified much more easily. The process freedom will be attained in freeing up labor-intensive manual labor involved in the quantity check-in and receiving processes [2].

\subsection{Manufacturing Flow Management and RFID}

In manufacturing, assembly line operations may get streamlined by using RFID. This automation in the production line will certainly reduce cycle time and increase production throughput. With enhanced process automation and tracking capabilities enabled by RFID, the velocity and visibility of products in the supply chain will likely improve [4]. This process will help manufacturers with their just-in-time (JIT) assembly lines. Procter \& Gamble (P\&G) believes that RFID technology can help the company to track where every item is in the manufacturing process and supply chain. P\&G expects the cost saving of up to $\$ 1$ billion in working capital and $\$ 200$ million in inventory carrying costs with its RFID implementation. Lee and Ozer [18] believe that the bottom-up approach, i.e., starting with the operating characteristics of the processes, is a sound way to assess the value of RFID.

\subsection{Returns Management and RFID}

The reverse logistics - product recall and return of defective products - is common in supply chain operations. The return track could be traced back very easily using RFID in the return process. RFID technology, through its smart Electronic Security Marker (ESM) can also facilitate return management by helping retailers know if they sold the item being returned. An ESM ties the relationship of a particular product to a given sale and then to the return. Manufacturers could benefit from the elimination of fraudulent products being returned to retailers by placing itemlevel RFID tags on their high end products and components [25]. Customer returns will add to the inventory pile as opposed to depleting it. These returns can be viewed as RFID providing downstream visibility of negative demands [18].

Figure 3 illustrates the challenges and values of RFID in the supply chains of firms. Internal process integration and interdependence in firms as well as external variables such as security, privacy, and standards play a vital role in moderating the effectiveness and efficiency of RFID. We discuss these factors in detail in the next section.

\section{Strategic Values, Challenges, and Recommendations for RFID Implementation}

There are a number of issues concerning the future of RFID with regard to the processes [27], [31]. These issues are related to complexity of process implementation, integration and interdependency of processes, and security of processes. Further research needs to be conducted to figure out how to enhance the range of RFID signals and figure out how to cut back on the interference issues. Furthermore, the solutions providers and consultants need to figure out how new smart labels, barcodes, and RFID equipment can work with customers' existing business practices [30]. One of the most challenging task facing companies adopting RFID technology is to properly integrate it with other information systems, both internally and externally, in their supply chain, and accordingly redesign their business processes that create strategic advantage. For example, given the capability of RFID in generating significant voluminous data compared to barcode technology, it would require new data warehousing systems to intelligently parse the usable data from the RFID data stream to ensure appropriate data processing and effective data mining at an economic storage cost. In particular, when a company extends its supply chain to upstream suppliers and downstream customers, their external integration needs to gain in capacity planning and in efficiency.

Security, privacy and integrity of the RFID system play a significant role in the type of supply chain application. In particular, as a wireless technology, RFID poses some potential security concerns to users when the communication between the tags and the reader is exposed to eavesdropping and traffic analysis. Security concerns may arise regarding the compromise of data during wireless transmission, storage of data, and physical security of storage site. Supply chain applications may be particularly vulnerable to security risk because a variety of external entities may have read access to the tags or related databases. For instance, the world's three largest seaport operators started to collaborate and deploy automated tracking, RFID-based detection and security technology for containers entering US ports [9], [22]. Theft prevention is another by-product of RFID. Quantification of such values has been researched by Lee and Whang [19]. Thus, while this wireless remote access is significantly beneficial, it can also create security 
risks if proper controls are not in place. RFID vendors have addressed some of these security issues through encrypting data transfers, blocking data transmissions through jamming, employing varying querying protocols, and blocker tag technique. A number of proposed RFID privacy-protection schemes are classified based on the new functionality they implement in RFID technology [24]. They range from adding only memory to adding lightweight circuits and each involves a trade-off between the cost of the tag and the value of privacy protection. The EPCglobal standard specifies that tags must be equipped with at least one nullification function, kill command, as a way to address public opposition by disabling the functionality of the tag after consumers purchase a product. It involves a high degree of consumer privacy protection at negligible cost but human error is always a possibility [24]. Privacy has been issue with RFID tags [12]. Other privacy-protection schemes generally reflect two main approaches: normal-tag and smart-tag. The normal-tag approach protects individual consumer privacy without having to modify the existing tag or cost the user organization more money. Smart tags are equipped with additional components such as rewritable memory, basic logic circuits, hash function units, and common-key/public-key encryption units [24].

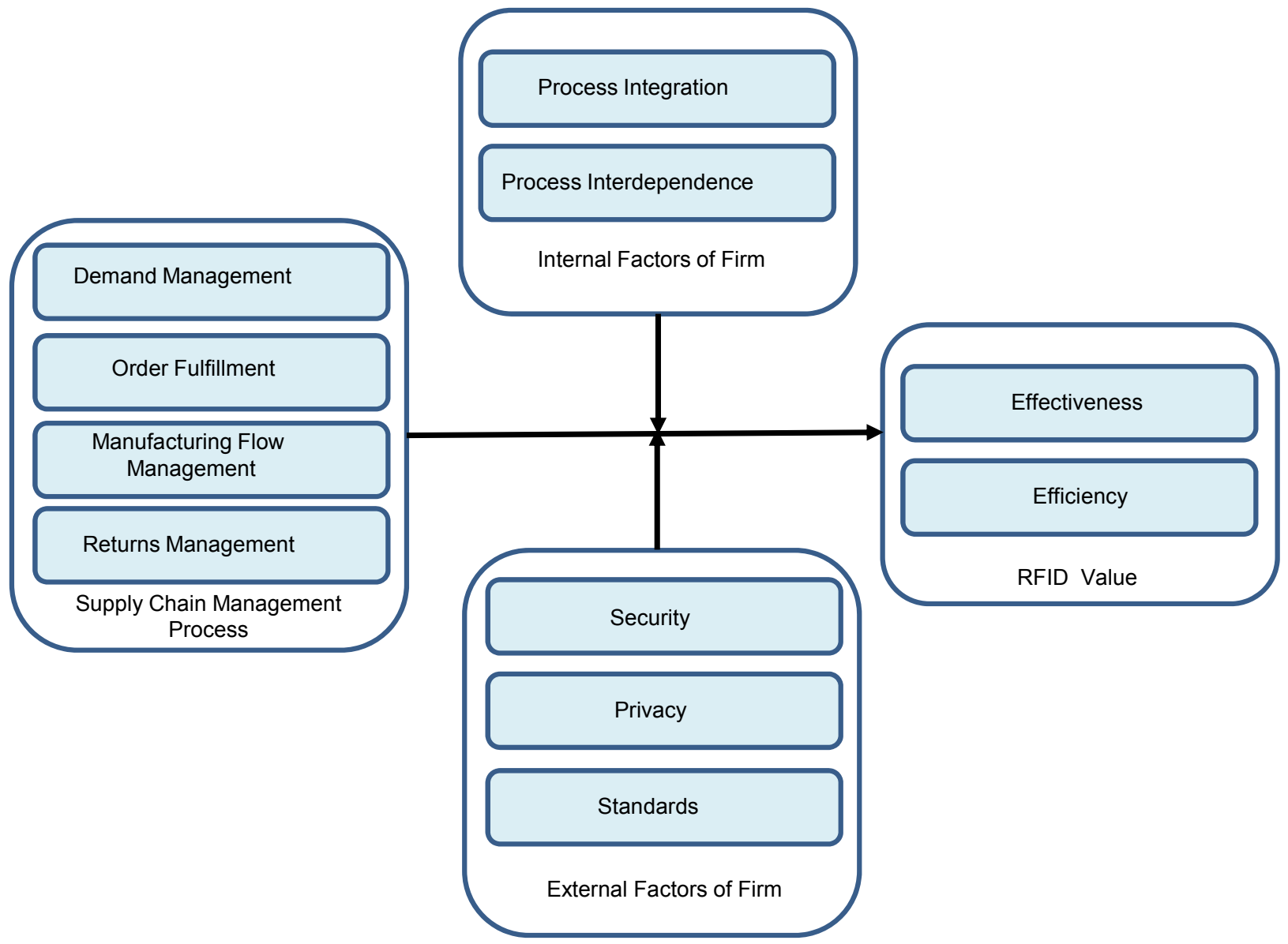

Figure 3: RFID value in SCM

Another challenge in adopting RFID technology in supply chain is multiple and sometimes conflicting standards that may hinder the technology's deployment and reduce its anticipated benefits. For example, while EPCglobal has developed a series of RFID application specifications and manages standardization for encoding information on RFID tags within the US, ISO has developed standards to address issues such as the "Generic Parameters for the Air interface for Globally Accepted Frequencies" and the "Parameters for the Air Interface Communications" at different operating frequencies [10]. Companies with supply chain extended to the global market may force to choose between standards and develop applications that might work under one standard and not the other. In this context, competing international standards between ISO and EPCglobal for deploying their standards is a concern. If various counties adopt significantly divergent RFID technologies, this would undermine interoperability of RFID and the software applications in tracking goods through the supply chain. In particular in global supply chain, this may encourage countries to mandate adoption of certain standards to protect internal market and to gain short-term economic gains rather than for technical reason. Thus, in order to enable the RFID technology in global supply chain, international interoperability of tags and readers and international spectrum allocation to facilitate international operability of technology needs to be addressed. In this context, it is critical that international regulatory processes remain transparent and nondiscriminatory in supporting RFID standards to ensure that these standards are based on technical merit and support interoperability. This will ensure that RFID technology will reach its potential economies of scale in the global supply chain. 


\section{Conclusion}

In this study, we have examined the effectiveness and efficiency of supply chain management in using RFID. We have also thoroughly examined appropriate business processes affected by RFID technology. Using four major supply chain processes, we highlight economic opportunities and challenges when planning and implementing RFID technology within an existing supply chain framework. RFID technology enables an organization to significantly change its business processes, not only to increase its efficiency which results in lower costs, but also increase its effectiveness, i.e. improving mission performance and makes the implementing organization more resilient and better able to assign accountability, as well as responding to customer requirements to use RFID technology to support supply chains and other applications. As discussed earlier, RFID offers significant strategic value potential for companies in developing an integrated model of supply and demand chain to drive revenues and innovation and to gain competitive advantage. Companies that implement the appropriate business processes to leverage the data collected by RFID and its conversion to information and intelligence will accelerate these benefits. As companies develop their RFID strategies, they must look beyond mere compliance for ways to implement these initiatives into their total supply chain strategy and harness the true business value of the technology, hastening profits.

\section{References}

[1] B. Anckar and D. D'Oncau, Value-added services in mobile commerce: An analytical framework and empirical findings from a national consumer survey, in Proceedings of 35th Hawaii International Conference on Systems Sciences, Big Island, HI, 2002.

[2] R. Angles, RFID technologies: Supply-chain applications and implementation issues, Information Systems Management, vol. 22, no. 1, pp 51-65, 2005.

[3] Z. Asif and M. Mandviwalla, Integrating the supply chain with RFID: An in-depth technical and business analysis, Communications of the Association for Information Systems, vol. 15, pp. 393-426, 2005.

[4] I. Bose and R. Pal, Auto-ID: Managing anything, anywhere, anytime in the supply chain, Communications of the ACM, vol. 48, no. 8, pp 100-106, 2005.

[5] J.L. Cavinato, What's your supply Chain Type? Supply Chain Management Review, pp. 60-66, May 2002.

[6] I. Clarke, Emerging value propositions for m-commerce, Journal of Business Strategies, vol. 18, pp. 133-148, 2001.

[7] M.C. Cooper, D.M., Lambert and J. D. Pagh, Supply chain management: More than a new name for logistics, The International Journal of Logistics Management, vol. 8, no. 1, pp. 1-14, 1997.

[8] K.L. Croxton, S.J. Garcia-Dastugue, D.M. Lambert and D.S., Rogers, The supply chain management processes, The International Journal of Logistics Management, vol. 12, no. 2, pp. 13-36, 2001.

[9] E.C. Cuneo. Safe at Sea, Information Week, April 7, 2003.

[10] Department of Commerce, Radio frequency identification, opportunities and challenges in implementation, Department of Commerce, Washington DC, 2005.

[11] A. Field, New thinking at IBM, Journal of Commerce, vol. 6, no. 14, pp. 22-27. 2005.

[12] R. A. Fusaro, None of our business? Harvard Business Review, vol. 82, no. 12, pp. 33-38, December 2004.

[13] A. Gunasekaran and E.W.T. Ngai, Build-to-order supply chain management: A literature review and framework for development, Journal of Operations Management, vol. 23, no. 5, pp. 423-451, 2005.

[14] M. Karkkainen, Increasing efficiency in the supply chain for short shelf life goods using RFID tagging, International Journal of Retail and Distribution Management, vol. 31, no. 10, pp. 529-536, 2003.

[15] T.B. Karygiannis, G. Eydt, L.B. Barber, and T. Phillips, Guidelines for securing radio frequency identification (RFID) systems: Recommendations of the National Institute of Standards and Technology, Information Technology Laboratory, National Institute of Standards and Technology, April 2007.

[16] P. Keen and R. Mackintosh, The freedom economy: Gaining the m-commerce edge in the era of wireless internet, New York: Osborne/McGraw-Hill, 2001.

[17] A. Kumar and G. Sharman, We love your product but where is it? Sloan Management Review, vol. 33, no. 2, pp. 93-99, 1992.

[18] H. Lee and O. Özer, Unlocking the Value of RFID, Production and Operations Management, vol. 16, no. 1, pp. 40-64, 2007.

[19] H. Lee and S. Whang, Higher supply chain security at lower cost: Lessons from Total Quality Management, International Journal of Production Economics, vol. 96, no. 3, pp. 289-300, 2005.

[20] J. Mears, Company hopes to tame Wal-Mart RFID requirement with IBM system, Network World, February, 2007.

[21] L. McCathie and K. Michael, Is it the end of barcodes in supply chain management? Proceedings of the Collaborative Electronic Commerce Technology and Research Conference, LatAm University of Talca, Chile, October 3-5, 2005, pp. 1-19.

[22] M. McHugh and P. Damas, Mega-Port Groups Back Security Pilot, American Shipper, pp. 4-18, September 2002.

[23] T.Neubauer, G. Goluch and B. Riedl, A research agenda for autonomous business process management, Proceedings of the 2nd International Conference on Availability, Reliability and Security, Vienna, Austria, pp. 670-680, 2007.

[24] M. Ohkubo, K. Suzuki and S. Kinoshita, RFID privacy issues and technical challenges, Communications of the ACM, vol. 48, no. 9, pp. 66- 71, 2005. 
[25] J. Pearson, Increasing Security in the Supply Chain with Electronic Security Markers", White Paper, Texas Instruments Radio Frequency Identification Systems, RFIDHF01, August 2006. [Online]. Available: http://ti.com/rfid/docs/manuals/whtPapers/wp eSecurity Markers.pdf.

[26] Rockwell Automation, RFID in Manufacturing, Rockwell Automation, 2004. [Online]. Available: http://www.glbinc.com/RFID whitepaper.pdf.

[27] A. Sabbaghi and G. Vaidyanathan, Efficiency of RFID in supply chain management: Strategic benefits and challenges, Issues in Information Systems, vol. 8, no. 2, pp. 443-448, 2007.

[28] P. Tarasewich, R. C. Nickerson and M. Warkentin, Issues in mobile e-commerce, Communications of the Association for Information System, vol. 8, pp. 41-64, 2002.

[29] N. Singh, Emerging technologies to support supply chain management, Communications of the ACM, vol. 46, no. 9, pp. 243-247, September 2003.

[30] G. Vaidyanathan, Automated identification and data collection in global supply chain, Proceedings of ISECON, vol. 22, Columbus, Ohio, 2005.

[31] D. Viehland and A. Wong, The future of radio frequency identification. Journal of Theoretical and Applied Electronic Commerce Research, vol. 2, no. 2, pp. 74-81, 2007. 